\title{
Imagen impactante, imagen rota: nota sobre el libro Striking Images, Iconoclasms Past and Present y la ambigüedad de la iconoclasia ${ }^{1}$
}

\author{
Striking images: \\ On the ambiguities of iconoclasm. \\ Remarks on the book \\ Striking Images, Iconoclasms Past and Present
}

\author{
HARIS CH. PAPOULIAS \\ Universidad del Piamonte Oriental, Italia
}

Recibido: 26/06/2016 Aceptado: 03/07/2016

\begin{abstract}
Actualmente, la reflexión sobre la imagen se centra mayoritariamente sobre su masiva presencia y su interminable reproducción. En este trabajo nos centraremos, a la inversa, en cómo las imágenes se destruyen masiva y sistemáticamente. Si el examen interdisciplinar es una prerrogativa fundamental en los estudios visuales, el volumen Striking Images, Iconoclasms Past and Present (Ashgate 2013), compilado por excelentes históricos y arqueólogos, ofrece a los filósofos un modelo importante de colaboración a la hora de pensar qué son las imágenes. El propósito de este trabajo es presentar y discutir brevemente algunos aspectos originales de estos ensayos, enfatizando la importancia de los distintos modos y motivos por los que nues-
\end{abstract}

1 Editado por Stacy Boldrick, Leslie Brubaker y Richard Clay. Editorial Ashgate, 2013; pp. XIV+236; ISBN: 978-1-4724-1367-3

(C) Contrastes. Revista Internacional de Filosofia, vol. XXI-N²2 (2016), pp. 171-181. ISSN: 1136-4076

Departamento de Filosofía, Universidad de Málaga, Facultad de Filosofía y Letras Campus de Teatinos, E-29071 Málaga (España) 
tros antepasados no solo han creado, sino también han destruido imágenes. Distinguiendo la iconoclasia del simple vandalismo, podemos descubrir una ambigüedad fundamental según la cual quien intenta preservar las imágenes, acaba con destruirlas y quien aparece como destructor, logra fertilizar nuevas concepciones y significados para su propia tradición figurativa. Quizás esta ambigüedad no sea algo que las imágenes sufren desde fuera, sino que sea algo connatural a la imagen misma. Y si es así, quien hoy estudia la vida de las imágenes, quizás podría encontrar un acceso privilegiado en esa a través una lógica paradójica que destaca como las imágenes mueren.

\title{
PALABRAS CLAVES \\ ICONOCLASIA, ICONOFÍLIA, FILOSOFÍA Y TEORÍA DE LAS IMÁGENES, ESTU- DIOS VISUALES.
}

\begin{abstract}
Contemporary thought on images focuses mostly on their massive presence and their endless reproduction. On the contrary, in this paper, I will focus on how images have been massively and systematically destroyed. If the interdisciplinary exam is a fundamental prerogative in visual studies, the volume Striking Images, Iconoclasms Past and Present (Ashgate 2013), compiled by excellent historians and archaeologists, could offer to philosophers an important frame of teamwork in thinking what the images are. The purpose of this paper is to present and discuss briefly some original aspects of these essays, by emphasizing the importance of means and reasons through which our ancestors have not only created, but also destroyed images. Once distinguished iconoclasm and mere vandalism, we could discover a fundamental ambiguity whereby any person who tries to preserve the images, finishes with wrecking them; while on the contrary somebody who appears as a destroyer, succeeds to fertilize new concepts and meanings for his/her own figurative tradition. Perhaps this ambiguity is not something that image suffers extrinsically, but something inherent to the image itself. And if it is so, he/she who wants to study the life of images, could perhaps find a privileged access to it, through a paradoxical logic that explains, instead, how images die.

KEYWORDS

ICONOCLASM, ICONOPHILIA, PHILOSOPHY AND THEORY OF IMAGES, VISUAL STUDIES.
\end{abstract}

LA AMBIGÜEDAD FUNDAMENTAL del fenómeno de la iconoclasia, se manifiesta ya en el mero intento de traducir el título de este libro en un idioma distinto del inglés; ya que striking puede significar tanto la acción de algo que "rompe", en el sentido literal de la palabra, como (en cuanto adjetivo) algo "llamativo", "impresionante", que "golpea" metafóricamente al observador: una "striking beauty" es una belleza impactante. Así, striking images podría significar tanto "rompiendo imágenes", como "imágenes impactantes”. ¿Es esto un juego de 
palabras fortuito? ¿O más bien nos indica algo intrínseco a la imagen misma, algo propio de su manera de ser?

A diferencia del volumen Iconoclasm from Antiquity to Modernity (Ashgate 2014) donde se esbozaba una historia de la iconoclasia en Occidente, en el volumen Striking images. Iconoclasms Past and Present (Ashgate 2013), editado por tres personalidades importantes en los estudios sobre iconoclasia (Boldrick, Brubaker y Clay) podríamos decir que el marco cronológico pasa como a un segundo plano. Sin embargo, el valor de esta obra reside en la amplitud geográfica del examen realizado y su tratamiento en nuevos marcos teóricos trans-históricos. En el libro hay ensayos que examinan tanto el Extremo Oriente y la América Latina, como Asia y la vieja Europa; no se trata de una historia, sino más bien una geografía conceptual de la iconoclasia.

En cuanto a la trans-historicidad de los ensayos, se puede observar la presencia de temáticas muy originales $\mathrm{y}$, por lo general, poco tratadas a nivel internacional. Además, hay que señalar el carácter teórico y filosófico de muchas intervenciones que van más allá de la mera investigación histórica y arqueológica. Después del primer ensayo introductorio de Boldrick, encontramos el ensayo Making and Breaking Images and Meaning in Byzantium and Early Islam (pp.13-25), firmado por una gran autoridad no sólo en los estudios de bizantinologia, sino en particular de la historia de la iconoclasia, Leslie Brubaker, (me limito solo a su obra Byzantium in the Iconoclast Era, Cambridge University Press: 2011). Gracias a su familiaridad con el tema, Brubaker logra mostrarnos en unas pocas páginas toda la importancia y la complejidad de este fenómeno: desde la imagen de los primeros siglos cristianos (utilizada como simple ayuda para la memoria) hasta el pleno desarrollo de la teoría de las imágenes en el siglo VIII, pasando por el uso siempre creciente de las reliquias (práctica ya establecida en el siglo $\mathrm{V}$ en un área geográfica que va desde España hasta Jerusalén). Rechazada la tesis de una origen común entre la iconoclasia bizantina y aquella islámica, la autora señala que "la prohibición, destrucción y reconstrucción [de las imágenes] ha contribuido en su conjunto a la creación de una red de significados", por lo que, paradójicamente, la iconoclasia bizantina acabó contribuyendo a la persistencia duradera de las imágenes mismas (p.23). Y es, en mi opinión, ésta "lógica paradójica" de la imagen el elemento que más que cualquier otro debería atraer hacia sí la reflexión sobre una filosofía de la imagen contemporánea.

El tercer capítulo del libro, Iconoclasm in European Prehistory? Breaking Objects and Landscapes (p.25-38), firmado por los arqueólogos Chapman y Gearey, nos lleva de nuevo a un tema muy poco conocido, pero de gran interés: la iconoclasia del paisaje. Los autores nos muestran cómo este tipo de iconoclasia es tan antigua como la humanidad. El concepto central de este trabajo es la iconoclasia como transformación intencional del paisaje. Aunque hallamos 
varios ejemplos procedentes de la antigüedad griega y romana, los autores van aún más lejos: ayudándose de su disciplina, la arqueología ambiental, llegan a conclusiones igualmente válidas en la prehistoria, donde las fuentes escritas están ausentes. Así, por ejemplo, en la deforestación realizada por los primeros agricultores del Neolítico, se puede reconocer la lucha con las poblaciones que aún vivían en estrecha dependencia de la selva, en cuanto cazadores. Choque de mentalidad que la iconoclasia representó también en la prehistoria con la destrucción (intencional y tal vez incluso ritual) de artefactos como espadas etc.; confirmando así, desde un nuevo punto de vista, que la destrucción, a veces, se dirige básicamente a la creación de nuevos significados para la comunidad.

En el cuarto capítulo (pp.39-46) The Buddha Head at Köfukuji Temple (Nara, Japan), Rambelli y Reinders nos llevan al Extremo Oriente, siguiendo el destino insólito de una estatua de Buda, por mucho tiempo ultrajada hasta su desaparición durante siglos y su reaparición en la colección de un museo. A partir de la larga historia de ataques sufridos por esta imagen), Rambelli y Reinders (que, además, son los expertos más importantes en la iconoclasia en el Extremo Oriente; véase, por ejemplo, su Buddhism and Iconoclasm in East Asia: A History, Bloomsbury: 2012), deducen un principio que nos puede conducir en todo estudio sobre nuestro asunto: "La iconoclasia", escriben, "raramente es un acto singular que oblitera totalmente el objeto" (p.40); incluye más bien "momentos de repetida contestación, apropiación, destrucción, restauración y amnesia". Nos invitan así a prestar atención a casos sutiles en los que los adversarios de las imágenes, no sólo no las destruyen, sino las protegen cuidadosamente (p.41), ya que a través de ellas logran una redefinición cultural y una inversión de sentido. Es muy curiosa la observación de los autores sobre la creación de una nueva estética a través de la iconoclasia, con la difusión de estatuas e imágenes sin cabeza o de cabezas solas sin cuerpo que, si para una cierta cultura New Age occidental puede parecer algo normal, en realidad, eso era impensable hasta el momento en la cultura oriental (p.44). A esto se une una de las observaciones más agudas del ensayo, en la que se identifican los museos como agentes morales de iconoclasia (p.45), porque precisamente en el hecho de salvaguardar el objeto material (su única preocupación) también destacan la violencia que éste objeto ha sufrido no sólo contra su aspecto, sino también contra su significado. A este fenómeno tan importante y tan sutil en su identificación, le han dado el nombre paradójico de preservación iconoclasta (p.46).

En el quinto capítulo nos trasladamos al otro lado del Pacífico. El historiador del arte O'Neil presenta el ensayo Marked Faces, Displaced Bodies: Monument Breakage and Reuse among the Classic-period Maya (pp.47-64). Aquí el autor se centra en dos tipos de actos iconoclastas: según uno de ellos, la imagen sólo se modifica; según el otro, la imagen se mutila por completo. Al examinar el primer modo (p.51s) el autor nos presenta otra definición, 
bella y paradójica: se trata de la "iconoclasia benévola" (p.52) que apunta a la neutralización de los poderes mágicos de las imágenes; o, como en los casos de imágenes conmemorativas de gobernantes antiguos, las cuales se deforman pero conservando intactos varios elementos y epígrafes, para que en el futuro se pueda identificar la desgracia del sujeto representado y permitir aún así un contacto con el pasado. Algo muy extraño en comparación con las formas de damnatio memoriae europea, donde a través la destrucción de la imagen, se pretende hacer desaparecer el pasado. De hecho, a diferencia de nuestra antigüedad clásica, donde una estatua o un templo en ruinas es la señal inequívoca del abandono de Dios, parece que en la civilización Maya, las imágenes, incluso destrozadas, continuaban recibiendo la devoción y las ofrendas de las personas (p.59).

Kim, en su ensayo Creative Iconoclasms in Renaissance Italy (pp.65-80), destaca el aspecto paradójico de una iconoclasia creativa, tratándolo como choque interno de una misma civilización (un criterio acertado, según mi opinión, para distinguir entre la iconoclasia y el vandalismo), examinando un período de la historia que hasta ahora siempre se ha considerado ajeno a cualquier asunto iconoclasta: el Renacimiento italiano. Es decir, el período que (después de la antigüedad griega y antes de la era de la imagen digital) produjo la mayor cantidad de imágenes significativas para la cultura occidental. Kim dirige nuestra mirada a las obras que a menudo pasan desapercibidas, como algunos frescos de las habitaciones vaticanas, en particular el de Giulio Romano (1499-1546), que representa a un escultor que destruye estatuas; o el de Tommaso Laureti (1530-1602), titulado El triunfo del cristianismo, ambos en la Sala de Constantino en el Vaticano. Es muy característico el ejemplo de las xilografías procedentes del Triompho di Fortuna por Sigismondo Fanti (1527), donde se representa a Miguel Ángel de manera ambigua en el acto de esculpir o destruir (según la interpretación que uno da) una pieza de mármol, lo que nos indica que "la violencia iconoclasta sigue vigente [in force]", pero "transmutada en vigor artístico [into the forza of Art]" (p.75). La autora relaciona todo esto con una especie de "iconoclasia filosófica" presente en los humanistas del Renacimiento, que anticipa de alguna manera la Ilustración; por lo que la lucha fundamental es en primer lugar entre el artista y su imaginación, sus propios ídolos mentales. Y es que en el Renacimiento se produjo una "iconoclasia suave" que dirigió sus impulsos destructivos no a la destrucción física sino a una reinvención radical de las formas artísticas (p.78).

Un enfoque parecido de la iconoclasia se muestra también en el séptimo ensayo, titulado Allegorical Tomb of Lord Somers: British Identity Built on Ruins? (pp.81-96) de Dudley. Si en la Italia católica, la iconoclasia se dirigió virtualmente contra los ídolos paganos, ahora, en la Inglaterra del siglo XVIII, la iconoclasia se dirige contra la Iglesia Católica. A través de una serie de 
obras de arte, entre las que podemos destacar el cuadro de Canaletto (p.83) Tumba alegórica de Lord Somers (1726), la autora reivindica el papel de la iconoclasia protestante en el proceso de construcción de la identidad británica como elemento diacrónico de la política cultural inglesa, como bien muestra el ejemplo de la Coventry Cathedral. Destruida la catedral por los bombardeos alemanes en los años 40 , se ha conservado deliberadamente en ruinas "como una especie de monumento al sacrificio" (p.93). Así es como lentamente emerge el aspecto iconoclasta "positivo", según el cual, dice la autora, iconoclasia no sólo significa "destrucción", sino también "apertura" al futuro.

La misma furia iconoclasta como arma contra la opresión de la Iglesia Católica se ha cultivado también en la Francia revolucionaria. Clay examina uno de los muchos eventos iconoclastas de aquellos tiempos: la destrucción de las reliquias de Santa Genoveva en París. En su ensayo Saint Geneviève, Iconoclasm and the Transformation of Signs in Revolutionary Paris (pp.97-112) se pueden encontrar muchos elementos que caracterizaron aquella iconoclasia política o ideológica de los revolucionarios parisinos. Una de las lecciones que los iconoclastas aprenden a menudo mejor que los iconófilos, tiene que ver precisamente con el poder de las imágenes que pretenden destruir. Teniendo esto en cuenta, no sorprende el destino particular de las imágenes en París: en un primer momento las reliquias de la santa se convierten en propiedad de una "Iglesia Republicana y Constitucional", es decir, se convierten en "propiedad de la nación"; el siguiente paso es fácil de adivinar: los que ahora vienen en adoración ofrecen así su aprobación tácita al nuevo status quo del régimen revolucionario (p.105).

De todos modos, la Ilustración significa para Occidente mucho más que una simple reacción a las imágenes del antiguo poder absolutista. Como argumenta Simpson en su Iconoclasm and the Enlightenment Museum (pp.113-28), con la Ilustración aparecieron al menos tres formas distintas de iconoclasia, precisamente en un intento de eludir el fracaso de aquella forma directa y violenta de iconoclasia llevada a cabo desde los primeros Reformadores. La primera de ellas es la iconoclasia filosófica, hija de la Ilustración científica (p.113) y contra la ideología. La segunda es la que neutraliza la imagen mediante su colocación en el museo (p.114); la tercera es la que logró cambiar la imagen bajo el martillo del mercado. Simpson se centra en la segunda forma y con gran habilidad identifica los secretos de pinturas donde todo lo sagrado y lo profano de Roma se junta y se coloca en un espacio neutral. Una estatua de Moisés ya no representa al iconoclasta bíblico o al rígido legislador religioso, sino simplemente la obra de Miguel Ángel y ahora se conserva y se admira según ésta calidad suya (p.115). La basílica de San Pedro representada en un cuadro adquiere un valor distinto: ya no es la que se construyó mediante la explotación de los fieles, como decía Lutero, sino una hermosa pintura, por- 
tátil, que ocupa una esquina de una galería, y está "inocentemente" dispuesta para ser vendida. Así es como suena la sentencia de Simpson en su inquietante verdad: "El espacio que protege el arte del martillo iconoclasta, lo vacía por igual de lo que ha sido su raison d'être" (p.117).

Con esto, el autor nos pone frente a una lógica más sutil de la destrucción banal o de la protección física de la obra de arte. Una lógica que continúa hoy en día animando cada aparecer de la imagen y que desmiente categóricamente a los que construyen muchos discursos vanos sobre la omnipresencia de la imagen en nuestra sociedad; porque el problema no es la divulgación o reproducción de las imágenes, sino la supervivencia o no de aquella raison d'être en relación con sus mismos aspectos formales. Simpson destaca la interdependencia entre la Ilustración y la Reforma, y lo hace a través de la categoría estética de gusto, sobre todo en dos autores importantes, crecidos ambos en ambientes protestantes: Hume y Kant. Ambos han desplazado el valor del juicio del gusto de los contenidos a la forma, de manera que una obra de arte católica podría ser nuevamente apreciada independientemente de su contenido y de los posibles peligros de la idolatría. "Concéntrate en la forma, deja a un lado el contenido. Degusta la libertad, incluso en el estudio del arte religioso. La categoría de lo estético, a fin de cuentas, es en sí misma un producto histórico de la iconoclasia" (p.119).

A pesar de la agudeza de estas observaciones, los problemas que surgen son aún mayores. En primer lugar, la relación entre la Ilustración y la Reforma, más allá de las similitudes aparentes, es de todos modos bastante ambigua, sobre todo si uno se aproxima a ella desde el debate sobre las imágenes. En la Ilustración, si por un lado es cierto que se vaciaba el contenido, por otro lado se reconocía a la forma un poder igual a lo religioso (es decir político), contribuyendo así a la creación de una nueva idolatría. Por otra parte, Lutero sabía algo del tema antes que Kant, como se evidencia en el trabajo que lleva adelante con el pintor Lucas Cranach contra el papado a través del pamphlet ilustrado Antithesis Figurata Vitae Christi et Anthichristi (1521). Si bien este folleto anticipa en siglos las modernas técnicas de propaganda por medio de la imagen, desde luego no es meramente por el valor formal de la imagen. De todos modos este discurso nos llevaría muy lejos con respecto al propósito del autor, que es mostrar cómo al proteger las imágenes, se las neutraliza.

En el ensayo de Noyes, Iconoclasm in the Twentieth Century: Machines, Mass Destruction, and Two World Wars (pp.129-44) nos encontramos al final de esta historia cultural de la imagen y, según una versión más pesimista, quizás estamos al final de la imagen misma, bien resumido por el nombre de "iconoclasia industrializada" o "iconoclasia total". Por un lado se pueden rastrear en casos como el bombardeo de Dresde por los Aliados, y por otro en las relaciones entre imagen y la idea misma del Estado moderno. Tras el final 
de la Guerra Fría y el cambio radical del mapa que este final trajo consigo, Noyes observó también un cambio radical en la naturaleza de la iconoclasia, ya que no tiene lugar a escala masiva, sino una vez más se convierte en una práctica de grupos pequeños de "non-state actors" contra objetivos igualmente individuales (p.142). Desafortunadamente, los recientes acontecimientos en el Medio Oriente con el Estado Islámico, desmienten parcialmente este camino. Tal vez no es casual que los terroristas individuales de ayer, hoy se agrupan en una entidad llamada "Estado". Quizás todavía es pronto para decir que hemos acabado con la idea del estado totalitario y solo en este sentido la lectura de Noyes resulta inactual; Palmira grita a la cara de Occidente las palabras de Hegel: "Lo que la experiencia y la historia enseñan es esto: que la gente y los gobiernos nunca han aprendido algo de la historia".

El ensayo de Elias The Taliban, Bamiyan, and Revisionist Iconoclasm (pp.145-64) se ocupa de la destrucción de los famosos Budas de Bamiyán por los talibanes en 2001, pero esta vez ofreciendo nuevo material al lector occidental, como declaraciones de prensa islámica de aquel período o la importancia simbólica de aquellos días según el calendario y las costumbres religiosas del Islam y que han tenido un papel importante en el curso de los acontecimientos. De gran interés son también las referencias a las tensiones internas del Islam (p.157s) que muestran que la iconoclasia no siempre fue inequívoca y unidireccional, incluso en el mundo árabe. De hecho se hacen ejemplos de iconoclasia extrema incluso contra los lugares donde vivió el Profeta o el lugar de entierro de su familia (p.158). Sin embargo, la declaración del autor acerca de un supuesto "espíritu iconoclasta", elemento común entre el "Islam, el judaísmo y una gran parte del cristianismo", creo que se pueda mostrar completamente errónea. Y esto no porque no hay lugares formales de posibles comparaciones para sostener tal cosa, sino porque, de hecho, estos lugares son solamente formales. Son escrituras muertas, mientras que lo que siempre ha diferenciado las culturas ha sido su interpretación. En estos casos podemos ver las consecuencias desastrosas de mentalidades formalistas: abstraer del contenido específico de la iconoclasia significa perder de vista su carácter esencial (y por lo tanto también el carácter de quien la practica y de quien es su víctima). Y puede ser cierto que gran parte de la prensa occidental a menudo es sensacionalista, pero eso no justifica la serie de acusaciones insinuadas contra Occidente, aunque sean siempre dentro de lo "políticamente correcto". Puede ser cierto que nadie en Occidente reaccionó ante la destrucción de mezquitas en India (como se lamenta en p.154) y que estábamos más preocupados por "piedras” (¡así suelen llamar algunos las estatuas de Bamiyán!) que por la desastrosa situación económica de la población afgana. Sin embargo, lo que Occidente ofrece al panorama mundial, no es un interés accidental de la prensa, sino algo que se llama derecho y protege incluso quien no comparte las herencias históricas 
de Occidente mismo. Si Occidente pudiera tal vez aparecer hipócrita, no sería con respecto a otros, sino con respecto a sí mismo. Y el ejemplo de Bosnia, citado por el autor, es una prueba, aunque por razones distintas de aquellas a las que Elias piensa (p.153). De hecho, podríamos recordar que Occidente ha estado allí para intervenir en favor de las minorías, mientras monasterios antiguos se derrumbaban, e igualmente desaparecían muchos patrimonios de la humanidad. Todo esto indica bien lo que podríamos llamar la "fragilidad de la cultura y de la democracia" de la que a menudo hablan los filósofos de la política: es decir, la fragilidad de una cultura que defiende los derechos de aquellos mismos que la amenazan. Sería suficiente, sin embargo, remitir al libro de Noyes (The Politics of Iconoclasm: Religion, Violence and the Culture of Image-Breaking in Christianity and Islam. Tauris: 2013, pp.158ss) donde todo eso se analiza en detalle.

Cambiando ahora completamente de registro, el duodécimo ensayo nos habla de otra "calidad iconoclasta" del arte. Baker empieza por la obra de artistas contemporáneos que revisitan lugares clásicos del arte (como grabados de Goya o dibujos animados) pero de manera "iconoclasta" y con una violencia asombrosa. Este tipo de iconoclasia, de hecho, se define mejor como un "proceso de transformación en signos" (p. 173). Lo que finalmente emerge es la extraña calidad del arte que se puede llamar "iconoclasta" en un sentido amplio, es decir la que proporciona placer a través del dolor; calidad con razón atribuible a un gran maestro de la literatura como Victor Hugo (p.178), y sin embargo todavía presente en el arte contemporáneo. De esta cualidad habló también Bataille con la expresión que da título a este ensayo: The cruel practice of Art (pp.165-82).

Antes del cierre del libro con el Saving images (The Fate of Bones), firmado por Boldrick y Barber (pp.199-206), donde se exponen las investigaciones recientes sobre iconoclasia, hay un último e inusual ensayo que merece nuestra atención. "Inusual", ya que está firmado por los que se enfrentan a la iconoclasia por profesión, es decir, el jefe restaurador del Victoria and Albert Museum de Londres, Ashlaey-Smith y el director ad interim de los museos de Birmingham, Cane. En este ensayo intitulado Iconoclasm as Conservation, Concealment and Subversion (pp.183-98), se destaca un aspecto curioso del trabajo del restaurador que mientras conserva y restituye la vida a un objeto dañado, inevitablemente provoca un cambio en su valor y significado. El restaurador es, muy a menudo, el responsable de una situación que describe bien el neologismo acuñado ad hoc por los autores: la museumification, es decir, la "museificación", el paso del uso cotidiano de un objeto a su exposición en un Museo. Además de eso, se trata también de una cuestión exquisitamente filosófica que interesó siempre los filósofos. Es decir, la cuestión de hasta qué punto se nos permite revivir lo que ya está muerto; porque, aun suponiendo que esto sea posible, ¿cómo habría que devolverle su forma perdida? 
Según Gadamer (Wahrheit und Methode, 1960), la historia del conflicto entre diversas hermenéuticas, parece que ha dado la razón a Hegel, quien argumentó en su Fenomenología del Espíritu (1807) que nada puede devolver la frescura del pasado. Esto se ha dicho contra una opinión típicamente romántica, como la de Schleiermacher, el que por el contrario creyó posible acceder a lo "original". Sólo para que nos entendamos: el palacio de Cnosos en Creta, reconstruido por Sir Arthur Evans, es el producto de esta mentalidad romántica; las columnas de la Acrópolis, son producto de una mentalidad "hegeliana", por así decir, por lo que las piezas añadidas por los conservadores de hoy son claramente distinguibles de las originales. Muy a menudo, el visitante de un museo, al contemplar las obras que cree originales, se encuentra en realidad frente a la manipulación causada por la conservación. De hecho, esta imposibilidad de darse cuenta de que, lo que se ve, no es el original sino el resultado de una mezcla de "ciencia, opinión artística y agudeza del juicio de la posteridad" (p.192) es una de las razones que llevan a los autores a hablar de "iconoclasia revisitada" porque ahora el objetivo es eliminar todo lo que no corresponde a la presunta imagen original, de hecho siempre idealizada.

El caso de una cruz celta, es muy sorprendente, ya que su propio estado después de su descubrimiento (plegada a consecuencia de una acción violenta) da testimonio de su pasado. Es muy probable que éste sea un hallazgo que da testimonio de los enfrentamientos crueles entre cristianos y paganos (p.188); por lo tanto, se excluyó categóricamente la posibilidad de restaurarla a su forma original, lo cual ocurre muy a menudo con otros artefactos en varios museos (p.194). Una tesis importante de los autores es que la restauración es "parte de la lucha continua por el control de las imágenes, de las cosas y de sus representaciones" (p.196). Aquí, en el mismo concepto de "conservación", se encuentran las raíces de toda de-contextualización museal o desmitificación-secularización de la imagen que ha sido tratada en los diversos ensayos del libro.

Para entender el significado completo de estas operaciones, hay que volver a subir hasta el horizonte conceptual filosófico. No sé cuál es el significado en el que los autores hablan (con desprecio) de la "posteridad de la filosofía con respecto a la práctica" (p.195); pero si es verdad - como decía Hegel - que "el búho de Minerva levanta el vuelo siempre al atardecer", esto se debe a que es privilegio del pensamiento poder hacer las cuentas con su pasado, interpretarlo libremente y no sufrirlo. Y para volver a nuestro tema, creo que libros como éste evidencian la capacidad reflexiva de nuestra civilización al sustraer las imágenes de la brutalidad de su destrucción física, incluso después de que esta destrucción haya tenido lugar, devolviendo su valor a través del pensamiento que comprende su significado. Es así como de una imagen rota, puede sobresalir una imagen impactante. 
Haris Ch. Papoulias es investigador doctoral en la Universidad del Piamonte Oriental (Italia) y aspirante a Doctor Europaeus (Universidad de Málaga, España). Realiza su tesis doctoral sobre la fundación de una teoría de la imagen en el sistema hegeliano.

Lineas de investigación:

la iconoclasia como categoría ontológica de la imagen; las relaciones entre arte y religión en la representación figurativa; la actualización de la filosofía hegeliana según las investigaciones contemporáneas sobre la imagen.

Publicaciones recientes:

«Forme di negatività nella Logica di Hegel», en: Annuario Filosofico (30) Milano: 2014. «On what is broken inside: Hegel on finitude», en: Truth and Experience. Between Phenomenology and Hermeneutics. Cambridge: 2015.

En preparación: «Hegel and the Image-theories of the Late Antiquity», Sevilla: 2016.

Email: haris.papoulias@unipmn.it 
